\title{
Opportunities of Interferon Therapy in Pregnant Women with Cervical Intraepithelial Neoplasia
}

\author{
Nina V. Zarochentseva ${ }^{1 \star}$, Julia M. Belaiya ${ }^{2}$, Lela K. Dzhidzhikhiya ${ }^{3}$, Valentina V. Malinovskaya ${ }^{4}$
}

\begin{abstract}
${ }^{1}$ Doctor of Sciences in Medicine, Professor of the Russian Academy of Sciences, Deputy Director for Scientific Work, Moscow Regional Research Institute of Obstetrics and Gynecology, Moscow, RUSSIA

${ }^{2}$ Candidate of Sciences in Medicine, Researcher, Polyclinic Department, Moscow Regional Research Institute of Obstetrics and Gynecology, Moscow, RUSSIA ${ }^{3}$ Candidate of Sciences in Medicine, Senior Researcher, Moscow Regional Research Institute of Obstetrics and Gynecology, Moscow, RUSSIA

${ }^{4}$ Doctor of Sciences in Biology, Professor, Head of the Laboratory, Laboratory of Ontogenesis and Correction of the Interferon System, National Research Center for Epidemiology and Microbiology named after Honorary Academician N.F. Gamaleya of the Ministry of Health of the Russian Federation, Moscow, RUSSIA ${ }^{\star}$ Corresponding Author: ninazar11@mail.ru
\end{abstract}

Citation: Zarochentseva NV, Belaiya JM, Dzhidzhikhiya LK, Malinovskaya VV. Opportunities of Interferon Therapy in Pregnant Women with Cervical Intraepithelial Neoplasia. Electron J Gen Med. 2021;18(5):em314. https://doi.org/10.29333/ejgm/11124

\section{ARTICLE INFO}

Received: 13 May 2021

Accepted: 24 Jul. 2021

\begin{abstract}
Objective: Due to hormonal and immune response changes, pregnancy contributes to their adverse stimulating effect on the progress of already existing hyperplastic processes in the cervix. The resulting aggravation of severity in their clinical course and intensity of the pathological process relatively frequently leads to precancerous conditions and cervical cancer developing further on. Some authors note the upward trend in the number of pregnant women having been diagnosed with pre-cancer and cancer of the cervix, as women postpone their maternity decisions increasingly more often. Currently, the tactics of managing pregnant women with cervical dysplasia consists in dynamic observation, including cytological study, colposcopic assessment of the state of surface cervical epithelium taking into account physiological particularities which are characteristic of pregnancy. The use of interferon therapy in pregnant female patients with HPV-associated cervical neoplasia is also expedient owing to its positive effect for reducing the CIN progression frequency, the probability of infecting the fetus with human papillomavirus, and the frequency of perinatal complications.

Methods: The study involved pregnant women in their second and third trimesters of gestation who have been diagnosed with cervical neoplasia (L-SIL, H-SIL). In comparison groups, behavior of cervical neoplasia was monitored against the background of the therapy conducted with interferon alpha- $2 \mathrm{~b}$ or without treatment.

Results: Against the background of the therapy conducted with interferon alpha-2b drug, higher frequency of the pathological process improving and lower frequency of its progressing into more severe dysplasia forms have been registered in the pregnant women with HPV-associated cervical neoplasia. However, it must be noted that efficiency of the treatment is higher in the group of pregnant women with L-SIL than in the H-SIL female patients. Conclusion: In managing the CIN pregnant women, it is expedient to prescribe interferon therapy systemically and topically in the form of gel $\left(\right.$ Viferon $\left.^{\circledR}\right)$ which allows reducing inflammation, viral load, ensuring regression of LSIL and stabilization of H-SIL.
\end{abstract}

Keywords: papillomavirus infection, pregnancy, L-SIL, H-SIL, interferon alpha-2b

\section{INTRODUCTION}

The incidence of $\mathrm{CIN}$ in pregnant women ranges from 3.4 to $10 \%$. In most pregnant women with dysplasia of the cervix, CIN $\mathrm{I}$ is registered, with severe dysplasia (CIN III) occurring less frequently - it is diagnosed in $0.1-1.8 \%$ of pregnant women. During pregnancy, $\mathrm{CIN}$ is found in young women more often [1]. Importantly, changes that are characteristic of CIN 1 improve after childbirth in approximately $60 \%$ of cases and remain unchanged in some 30\%. Progression toward more complicated lesions (CIN III) is registered rarely - in $6 \%$ of female patients at the maximum. With $\mathrm{CIN}$ III, the regression percentage after childbirth is low - about $30 \%$, and progression is observed in approximately $10 \%$ of female patients. CIN III and pre-invasive cervical cancer both have no clear clinical picture and are detected during morphological examinations [2], which demands timely compulsory anti-inflammatory therapy and differential diagnosis. Pregnant female patients diagnosed with CIN II-III have various speed of progression into the invasive CC. In their works, Ackermann S. and Everson J.A. reported about the progression speed of $2.4 \%$, while Coppola et al. - a higher level, 8\% [3].

It is important to bear in mind immunological and physiological changes of the cervix during pregnancy (plethora, congestive phenomena, swelling) - they frequently lead to hyper-diagnosing and irrelevant surgical intervention. However, an experienced specialist must always remember oncological alertness and correctly follow the management algorithm for female patients with a pathology found $[4,5,6]$.

Over the recent years, the contemporary tactics of treating pre-cancerous diseases of the cervix in pregnant women has changed - from aggressive surgical handle toward a conservative approach [7]. As the progression rates during pregnancy are low, it is currently common to believe that for 
most female patients, expectant tactics will be safe for the entire gestation term, provided that invasive process has been ruled out, because the risk of its progressing into invasive cancer is extremely low $-0.0-0.4 \%$ - within such a brief time span [7]. So, it is ruling out invasive cancer that is the most important and highest-priority in tailoring management tactics for pregnant female patients with CIN III and pre-invasive cancer. In the cytological screening study, detection of atypical cells is an indication for colposcopy, when the necessity and location of target biopsy can be identified. According to SOGC joint clinical practice guideline of 2012, if CIN II-III is suspected or diagnosed during pregnancy, the repeated colposcopy should be conducted, and the treatment has to be postponed up to 8-12 week after childbirth. Concerning subsequent observation after the conducted treatment for CIN II-III, it is determined: women should undergo testing - cytological study of the cervix and colposcopy - 1 time each 6 months at the interval of 2 visits. If the cytology and biopsy results return negative, the women are put back on the screening schedule set by local recommendations [8]. Conization of the cervix can be performed in 6-8 weeks after childbirth9. If a woman has a high-grade dysplasia of the cervix, the mode of delivery only depends on obstetric reasons. When CIN III is detected in the first trimester, and there is no wish to keep the pregnancy medical abortion is performed, with conization of the cervix in 4-8 weeks; if the woman wishes to keep the pregnancy - it is maintained, with conization of the cervix in 4-8 weeks after vaginal delivery. If invasive growth is suspected, medical abortion and conization of the cervix in 4-8 weeks are indicated, with atypical or wedge-shaped conization performed in case of an express desire to keep the pregnancy [9]. When CIN III is found during the second and third trimesters, it is expedient to maintain the pregnancy and perform cervical conization in 6-8 weeks after vaginal delivery [9].

In their works, a number of foreign researchers report a much higher speed of postpartum regression of CIN in the group of pregnant women as compared to groups of nonpregnant female patients. Some authors have supposed that in women with HPV-infection, their typical endocrine profile during pregnancy induces activation of the virus, which subsequently results in a higher speed of its spontaneous regression after childbirth [10]. In the study by D. Ahdoot et al. [11], it is demonstrated that the regression speed was higher in the women who had undergone biopsy of the cervix within prenatal assessment, as compared to the women subjected to biopsy (70\% versus 52\%).

Other studies give evidence about correlation between CIN and mode of delivery: they have found a higher speed of regression of cervical dysplasia after vaginal delivery as compared to Caesarean section (67\% as compared to $13 \%)$ [12]. A possible mechanism thereof can be associated with the loss of dysplastic cervical epithelium during ripening, opening of the cervix, and passage of the fetus through birth canals.

At present, approaches to management of pregnant women having structural pathologies of the cervix are worded clearly enough. However, there is no uniform opinion as for the efficiency of treating HPV-associated diseases of the cervix during pregnancy, especially since no specific drugs to suppress replication of all HPV types have been developed in the world yet. On top of that, the use of many medicinal products is limited during pregnancy. One of the factors determining the outcome of an HPV-associated disease of the cervix is the imbalance of cell-to-cell interaction of local immunity factors, the regulation mechanism of which is closely connected to production of cytokines [13]. On the one hand, HPV is known to feature a poor enzyme array as compared to other viral infections and to have no own polymerases which could be the target for antiviral drugs. On the other hand, there is information that in case of HPV and CIN, dysfunction of both T-system and B-system of the immune response develops, the defect of interferon system is observed, and the balance of proand anti-inflammatory cytokines is changed. In female patients having L-SIL and H-SIL, the 5-fold increase of concentration of IL-1a and IL- $1 b$ has been found against the background of a low IL-8 and TNF-alpha level. Hence, the range of effect drugs can have on the immune system has to be borne in mind when selecting conservative therapy for $\mathrm{CIN}[14,15]$. According to the data given by $\mathrm{K}$. Torres-Poveda et al., HPV reduces the expression of interferon and enhances the activity of interleukin-10 and transforming growth factor $\beta 1$ (TGF- $\beta 1$ ), thus forming a local immunosuppressive environment. This is why increasing the interferon level is believed to be expedient in the management tactics [16]. In terms of pathogenesis, the use of immunomodulating agents with antiviral and antiproliferative effect is justified [14].

In pregnant women having HPV, the condition of immune system was studied by a group of researchers in Moscow region [17]. They observed disorder of tissue immunity (valid increase of the content of IgG, change of anti-inflammatory cytokine levels that were especially pronounced under high-risk HPV) in the group under study. According to the study conducted, the presence of HPV in pregnant women was accompanied by abrupt decrease of tissue immunity that was most pronounced against the background of persistent high-risk cancerassociated human papillomaviruses, which manifested itself in production of secretory immunoglobulin A going down and production of IgG increasing by 2 times and more [17]. The 2014 study reports the use of combined treatment with Viferon ${ }^{\circledast}$ drug (recombinant interferon alpha-2b), in the form of rectal suppositories and intravaginal introduction of gel, to have a clear positive effect on the condition of tissue immunity and to ensure antiviral protection [17]. Owing to its combined composition, Viferon ${ }^{\circledR}$ features a number of effects: when applied with membrane stabilizing drugs, the antiviral activity of recombinant interferon increases 10-14 times, its immunomodulating action on T- and B-lymphocytes is enhanced, the content of immunoglobulin $\mathrm{E}$ is normalized, and there are no side effects (higher temperature, fever, flu-like symptoms) occurring in parenteral administration of interferon drugs. Antioxidant components of Viferon ${ }^{\circledR}$ ascorbic acid and $a$-tocopherol acetate - regulate oxidationreduction processes in the organism, its carbohydrate metabolism, promote tissue regeneration, and participate in biosynthesis of proteins and tissue respiration, which is essential for a high efficiency of treatment. Moreover, according to the label, the drug can be used not only in pregnant women, but also in neonates.

\section{METHODS}

\section{Objective of the Research}

Objective of the research: optimizing the management tactics of pregnant women with HPV-associated cervical neoplasia by using interferon alpha- $2 \mathrm{~b}$. 


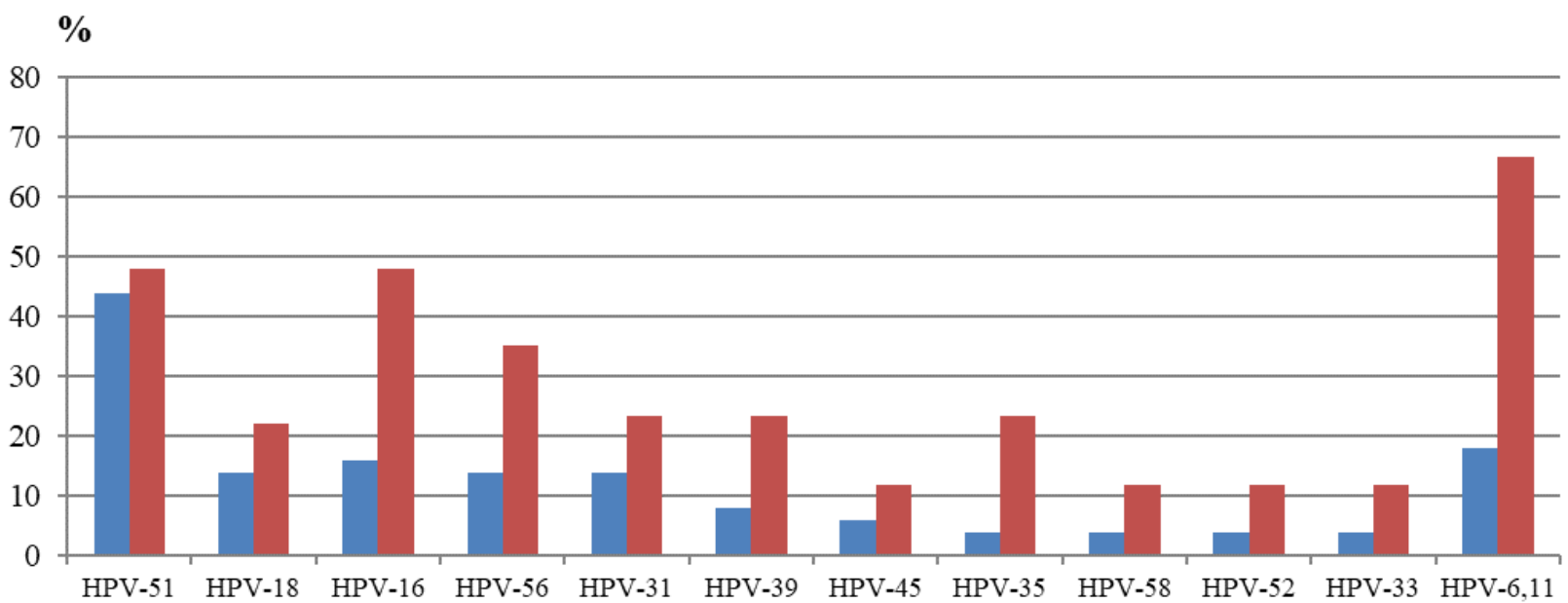

Figure 1. Detection frequency of virus types in the female patients of comparison groups at the end of the study Source: compiled by the authors

Table 1. Comparative data of PCR-based diagnostic findings in observation groups

\begin{tabular}{|c|c|c|c|c|}
\hline & \multicolumn{2}{|c|}{ Group I (n=94) } & \multicolumn{2}{|c|}{ Group II (n=97) } \\
\hline & $\begin{array}{l}\text { At the beginning of the } \\
\text { study }\end{array}$ & At the end of the study & $\begin{array}{l}\text { At the beginning of the } \\
\text { study }\end{array}$ & At the end of the study \\
\hline Chlamydia trach., $\mathbf{n}(\%)$ & $9(9.6 \%)$ & - & $11(11.3 \%)$ & $2(2.1 \%)$ \\
\hline Mycoplasma gen., n (\%) & $20(21.3 \%)$ & - & $25(25.8 \%)$ & $3(3.4 \%)$ \\
\hline Ureaplasma spp./parv., $\mathbf{n}(\%)$ & $36(38.3 \%)$ & $13(13.8 \%)$ & $34(35 \%)$ & $19(19.6 \%)$ \\
\hline Gardnerella vaginalis, n (\%) & $49(52.1 \%)$ & - & $44(45.4 \%)$ & $8(8.2 \%)$ \\
\hline
\end{tabular}

Source: compiled by the authors

\section{Tasks of the Research}

Tasks of the research conducting treatment of pregnant women with HPV-associated cervical neoplasia (L-SIL, H-SIL) and evaluating efficiency of the therapy as compared to female patients who did not receive treatment.

\section{Methods of the Research}

Based on Moscow Regional Research Institute of Obstetrics and Gynecology, examination and observation of pregnant women in their second and third trimesters of gestation ( $n=191)$ was conducted in the scientific consulting department. In all the female patients, HPV-associated cervical neoplasia was diagnosed in the first trimester of gestation when registering with the female health department.

Group I consisted of pregnant women ( $n=94$ : L-SIL $(n=48)$ and H-SIL $(n=46)$ ) who received a course of therapy with interferon alpha-2b (Viferon ${ }^{\circledR} 500000$ ME suppositories by rectal administration 2 times per day for 10 days, and Viferon ${ }^{\circledR}$ $36000 \mathrm{ME}$ gel by intravaginal introduction for 10 days) starting with the second trimester of gestation within 13-14 week, 2224 week, and 32-34 week terms.

Group II (the historical observation one, $n=97$ ) was made up of female patients with cervical neoplasia (L-SIL $(n=47), \mathrm{H}-\mathrm{SIL}$ $(n=50))$ who visited the institute at full-term gestation, without the interferon alpha- $2 b$ therapy prescribed during this pregnancy.

The study results were evaluated before delivery and in 6-8 weeks after delivery.

\section{RESULTS}

The average age of the female patients was 25 . In the majority of them $(67.5 \%)$, this pregnancy was the consecutive one. The following findings have been obtained as a result of the study conducted.

In PCR-based diagnosing, isolation frequency of highly oncogenic HPV types was 2 times higher in the pregnant women of group II, except type 51 virus which was detected at the same frequency in both groups. Low-risk virus types 6 and 11 were found in the pregnant women who had no interferon therapy 3.5 times more frequently (Figure 1 ).

In the female patients of comparison groups, laboratory examination findings have shown statistically significant distinctions according to STD detection frequency and vaginal biocenosis disorder in comparison groups (Table 1).

Pregnant women's with HPV and urogenital infection leads to the abrupt decrease of the tissue immunity, which is in line with data of many researchers; this study confirms this fact, too. The characteristic features found are the extremely low production of sIgA and a high level of IgM in the pregnant women of group II, which confirms marked changes of the tissue immunity.

It should be noted that more pronounced inflammatory changes have been found in the female patients of group II, as well as in the H-SIL subgroups of both groups.

TNF is known to be a positive regulator of inflammatory reaction and a trigger factor in the cytokine production chain. The levels of TNF, IL-6, and IL-8 which account for non-specific immunity were validly higher in the pregnant women of group 
Table 2. Behavior of immunological indicators in group I pregnant women at the beginning and end of the study

\begin{tabular}{|c|c|c|c|c|}
\hline \multirow[b]{2}{*}{ Indicators } & \multicolumn{2}{|c|}{ At the beginning of the study } & \multicolumn{2}{|c|}{ At the end of the study } \\
\hline & L-SIL(n=48) & H-SIL(n=46) & L-SIL(n=48) & H-SIL(n=46) \\
\hline slgA (mg/l) & $4.1 \pm 0.3$ & $3.2 \pm 0.2$ & $8.4 \pm 0.5$ & $6.8 \pm 0.6$ \\
\hline $\operatorname{lgM}(\mu \mathrm{g} / \mathrm{ml})$ & $18.4 \pm 1.1$ & $19.5 \pm 01.3$ & $11.9 \pm 0.8$ & $12.6 \pm 0.9$ \\
\hline $\operatorname{lgG}(\mu \mathrm{g} / \mathrm{ml})$ & $1937.2 \pm 46.3$ & $1838.4 \pm 44.9$ & $1025.4 \pm 44.2$ & $1116.3 \pm 42.1$ \\
\hline TNF- $\alpha$ (pg/ml) & $28.1 \pm 1.4$ & $31.6 \pm 1.6$ & $11.8 \pm 0.6$ & $12.1 \pm 0.6$ \\
\hline IL-6(pg/ml) & $24.2 \pm 1.2$ & $29.1 \pm 1.4$ & $31.9 \pm 1.4$ & $35.8 \pm 1.5$ \\
\hline IL-8 (pg/ml) & $1977.2 \pm 46.3$ & $2118.7 \pm$ & $1443.2 \pm 45.4$ & $1516.1 \pm 45.8$ \\
\hline
\end{tabular}

Source: compiled by the authors

Table 3. Content of cytokines in comparison groups at the end of the study

\begin{tabular}{|c|c|c|c|c|}
\hline \multirow[b]{2}{*}{ Indicators } & \multicolumn{2}{|c|}{ Group I (n=94) } & \multicolumn{2}{|c|}{ Group II (n=97) } \\
\hline & L-SIL(n=48) & H-SIL(n=46) & L-SIL(n=47) & H-SIL $(n=50)$ \\
\hline $\operatorname{slgA}(\mathrm{mg} / \mathrm{l})$ & $8.4 \pm 0.5$ & $6.8 \pm 0.6$ & $2.4 \pm 0.4$ & $1.9 \pm 0.4$ \\
\hline $\operatorname{lgM}(\mu \mathrm{g} / \mathrm{ml})$ & $11.9 \pm 0.8$ & $12.6 \pm 0.9$ & $19.4 \pm 0.7$ & $27.8 \pm 1.1$ \\
\hline $\operatorname{lgG}(\mu \mathrm{g} / \mathrm{ml})$ & $1025.4 \pm 44.2$ & $1116.3 \pm 42.1$ & $1428.1 \pm 36.8$ & $1684.2 \pm 41.6$ \\
\hline TNF- $\alpha$ (pg/ml) & $11.8 \pm 0.6$ & $12.1 \pm 0.6$ & $14.3 \pm 0.7$ & $16.8 \pm 0.5$ \\
\hline IL-6(pg/ml) & $31.9 \pm 1.4$ & $35.8 \pm 1.5$ & $39.2 \pm 1.7$ & $44.1 \pm 1.4$ \\
\hline IL-8 (pg/ml) & $1443.2 \pm 45.4$ & $1516.1 \pm 45.8$ & $1914.7 \pm 44.9$ & $2358.9 \pm 45.6$ \\
\hline
\end{tabular}

Source: compiled by the authors

Table 4. Behavior of cytological test in pregnant female patients during gestation depending on the management tactics preferred

\begin{tabular}{|c|c|c|c|c|c|c|}
\hline & \multicolumn{2}{|c|}{ Group I (n=94) } & \multicolumn{4}{|c|}{ Group II (n=97) } \\
\hline & L-SIL, \% & H-SIL (CINII), \% & \multicolumn{2}{|c|}{ L-SIL, \% } & \multicolumn{2}{|c|}{ H-SIL (CIN II), \% } \\
\hline At the beginning of the treatment & $100(n=48)$ & $100(n=46)$ & \multicolumn{2}{|c|}{$100(n=47)$} & \multicolumn{2}{|c|}{$100(n=50)$} \\
\hline After treatment & $50(n=24)$ & $91.3(n=42)$ & \multicolumn{2}{|c|}{$74.5(\mathrm{n}=35)$} & \multicolumn{2}{|c|}{$76(n=38)$} \\
\hline \multirow{2}{*}{ Progression to a high grade } & - & - & CIN II & CIN III & CIN III & Cr in situ \\
\hline & - & - & $12.7(n=6)$ & $10.6(n=5)$ & $18(n=9)$ & $2(n=1)$ \\
\hline \multirow{2}{*}{ Postpartum period } & L-SIL, \% & H-SIL (CINII), \% & \multicolumn{2}{|c|}{ L-SIL, \% } & \multicolumn{2}{|c|}{ H-SIL (CINII), \% } \\
\hline & $41.7(20)$ & $84.4(n=39)$ & \multicolumn{2}{|c|}{$66(n=31)$} & \multicolumn{2}{|c|}{$68(n=34)$} \\
\hline \multirow{2}{*}{ Progression to a high grade } & - & - & CIN II & CIN III & CIN III & Cr in situ \\
\hline & - & - & $14.9(n=7)$ & $19.1(n=9)$ & $20(n=10)$ & $2(n=1)$ \\
\hline
\end{tabular}

Source: compiled by the authors

II, as well as in the H-SIL female patients of both groups (see Tables 2, 3).

The data of cytokine content analysis give evidence about a high content of interleukins being more frequent in group II without the use of interferon alpha- $2 b$, which is a sign of immunopathological process and powerful inflammation in group II of the study (Tables 2, 3). Given the absence of the data on cytokine and interferon status in group II female patients at the beginning of the study, with the purpose of evaluating the efficiency of interferon alpha-2b, the behavior of these indicators have only been analyzed in the female patients of group I. Analysis of the findings has shown that inclusion of interferon therapy into management of pregnant female patients with CIN allows improving the tissue immunity indicators validly, which subsequently determines the course of CIN (Table 2).

The results obtained confirm that the tissue immunity disorder extent is directly related to the severity of cervical pathology caused by HPV.

When the repeated cytological study was conducted in group I of the female patients at the end of pregnancy, signs of L-SIL have been found in 50\% of the female patients already, and those of $\mathrm{H}-\mathrm{SIL}$ - in $91.3 \%$ of the pregnant women. No progression to a more severe neoplasia grade has been observed in the female patients of this group.

In group II of the study, at the end of treatment, $74.5 \%$ of the female patients have kept signs of L-SIL, and $76 \%$ of the pregnant women - signs of H-SIL. 11 of the L-SIL female patients (CIN II has been found in 12.7\%, and CIN III - in 10.6\%) have had progression to a more severe grade of neoplasia, and so have $11 \mathrm{H}$-SIL women (22\%). Meanwhile, in $18 \%$ of the pregnant women, CIN III has been detected, and in one female patient $(2 \%)$, the neoplasia has transformed into $\mathrm{cr}$ in situ (Table 4).

In the postpartum period, regression has been registered in group I female patients more frequently, while progression - in group II of the study.

\section{DISCUSSION}

The relevance of the problem of cervical intraepithelial neoplasia in gestation is beyond doubt, given its incidence, complications during pregnancy, and perinatal outcomes.

Analysis of the findings obtained in the course of this study has shown that at the beginning of observation, HPV was accompanied by bacterial vaginosis in $44-49 \%$ of the pregnant women of both groups, by the Chlamydia infection - in 9-11\%, and in $20-36 \%$ of the female patients, the Mycoplasma and Ureaplasma colpitis was found. At the end of the study, the frequency of detection of the accompanying urogenital infection prevailed in group II (who had no interferon therapy). By contrast, in the group of pregnant female patients who received treatment, no pathogens were found except Ureplasma spp./parv. 
In pregnant female patients with cervical intraepithelial neoplasia, the interferon therapy conducted has allowed improving immunological indicators over time in female patients of group I. In them, higher content of secretory immunoglobulin A and IL6, as well as lower levels of IgM, IgG, and TNF- $\alpha$, plus IL8, were registered. Meanwhile, with immunological indicators of both groups compared at the end of the study, it can be stated with confidence that the result was better where interferon therapy was conducted, too. The difference of immunological indicators in the comparison groups enables one to make sure that in HPV-positive pregnant female patients, interferon therapy furthers improvement of the said indicators.

The cytological study findings allow making the following conclusion: regression of L-SIL has taken place in $50 \%$ of group I female patients and in $25.5 \%$ of group 2 pregnant women; persistence of $\mathrm{H}$-SIL has been registered in $91.3 \%$ of group 1 female patients and in $76 \%$ of group 2 ones. However, it should be noted that progression of neoplasia to a more severe grade has only been diagnosed in the female patients of group 2 .

In the postpartum period, the frequency of dysplasia went down in both groups. Meanwhile, in the postpartum period, progression of neoplasia to a more severe grade was only diagnosed in the female patients without interferon therapy just like during pregnancy.

The results of the study conducted have enabled the authors to make sure that between the comparison groups, the difference of the pathology detected and the course of papillomavirus infection is evident. The frequency of detecting the accompanying urogenital infection is higher in the group having no interferon therapy than in the observation and treatment group. The course of HPV-associated precancerous diseases of the cervix in pregnant women is less aggressive against the background of interferon therapy, which is manifested in greater percentage of HPV elimination and regression or stabilization of cervical neoplasia.

\section{CONCLUSION}

Thus, prevalence of HPV, diversity of pathological conditions, and the potential risk of malignant transformation of the cervical epithelium determine high significance of cervical intraepithelial neoplasia occurring and developing in the gestation period. The work practice has shown that conization of the cervix, which may lead to spontaneous abortion, premature birth, bleeding, and other gestational complications, can be avoided when conducting cytological screening of pregnant women and in case a picture corresponding to moderate and high-grade cervical dysplasia and even cancer in situ is identified in the smears. Nowadays, the tactics of managing pregnant women with cervical dysplasia consists in dynamic observation, including cytological study, colposcopic assessment of the state of surface cervical epithelium taking into account physiological particularities which are characteristic of pregnancy, alongside the use of immunomodulating therapy aimed at immune status correction both at the local and systemic levels.

In managing the CIN pregnant women, it is expedient to prescribe interferon therapy systemically and topically in the form of gel (Viferon $\left.{ }^{\circledR}\right)$ which allows reducing inflammation, viral load, ensuring regression of L-SIL and stabilization of H-SIL. In this study group, the female patients had no progression of cervical neoplasia, unlike those without interferon therapy.

Author contributions: All authors have sufficiently contributed to the study, and agreed with the results and conclusions.

Funding: No funding source is reported for this study.

Declaration of interest: No conflict of interest is declared by authors.

\section{REFERENCES}

1. Skrzypczyk-Ostaszewicz A, Rubach M. Gynaecological cancers coexisting with pregnancy - a literature review. Contemp Oncol (Pozn). 2016;20(3):193-8. https://doi.org/10.5114/wo.2016.61559 PMid:27647981 PMCid:PMC5013680

2. Golitsyna YS, Shmakov RG, Khabas GN, Ovodenko DL. Cervical cancer and pregnancy: main principles of diagnosing, treating, and managing pregnancy. Doctor.ru Gynecology Endocrinology. 2018;2(146):15-9.

3. Ackermann S, Gehrsitz C, Melhorn G, Beckman MW. Management and course of histologically verified cervical carcinoma in situ during pregnancy. Acta Obstet Gynecol Scand. 2006;85:1134-7. https://doi.org/10.1080/00016340 600555926 PMid:16929422

4. Atabieva AD, Pikuza TV, Chilova RA, Zhukova EV, Trifonova NS. Diseases of the cervix and modern methods for their diagnosis (review of literature). The Bulletin Contemporary Clinical Medicine. 2016;9(4):72-83. https://doi.org/10.20969 /VSKM.2016.9(4).72-83

5. Dobrokhotova YE, Venediktova MG, Borovkova El, Danelyan SZ, Sarantsev AN, Morozova KV, Orudzhova KF. Methods of diagnosing and treating borderline cervical cancer associated with pregnancy. Russian Journal of Women and Child Health. 2017;15:1084-6.

6. Pikuza TV, Chilova RA, Kaptiln'yy VA, Chushkov YV, Tkacheva MV. Pathology of the cervix uteri in pregnant women: examination and treatment tactics (literature review). Gynecology. 2016;18(2):11-8. https://doi.org/ 10.26442/2079-5696_18.2.11-18

7. Mailath-Pokorny M, Schwameis R, Grimm C. Natural history of cervical intraepithelial neoplasia in pregnancy: postpartum histo-pathologic outcome and review of the literature. BMC Pregnancy and Childbirth. 2016;16:74-82. https://doi.org/10.1186/s12884-016-0861-8 PMid:27055819 PMCid:PMC4825080

8. Krasnopolskiy VI, Korolenkova LI, Zarochentseva NV, Zhordania KI, Shchukina NA. Obligate forms of precancer and cervical cancer: a guideline for doctors. Moscow: SIMK; 2017.

9. Urmancheeva AF, Ulrikh EA. Tumors of female genital organs and pregnancy. St.Petersburg: N-L; 2011.

10. Serati M, Uccella S, Laterza RM. Natural history of cervical intraepithelial neoplasia during pregnancy. Acta Obstet Gynecol. 2008;87:1296-300. https://doi.org/10.1080/ 00016340802482986 PMid:18951206

11. Ahdoot D, Van Nostrand KM, Nguyen NJ. The effect of route of delivery on regression of abnormal cervical cytologic findings in the postpartum period. Am J Obstet Gynecol. 1998;178:1116-20. 9378(98)70310-2 https://doi.org/10.1016/S0002- 
12. Mailath-Pokorny M, Schwameis R, Grimm C. Natural history of cervical intraepithelial neoplasia in pregnancy: postpartum histo-pathologic outcome and review of the literature. BMC Pregnancy and Childbirth. 2016;16:74-85. https://doi.org/10.1186/s12884-016-0861-8 PMid:27055819 PMCid:PMC4825080

13. Marochko KV, Artymuk NV. Opportunities of interferon therapy in treating women infected with high-risk human papillomavirus. Mother and Baby in Kuzbass. 2017;1(68):28-33.

14. Mezhevitinova EA, Kostava MN, Abakarova AE, Donnikova AE. Opportunities of immune therapy of HPV-associated diseases of the cervix. Gynecology. 2018;1:40-5.
15. Zarochentseva NV, Belaiya JM, Malinovskaya VV. Combined use of interferon alpha-2B drugs with tetravalent vaccine against reinfection in HPV female patients Electronic Journal of General Medicine. 2020;17(6):1-5. https://doi.org/10.29333/ejgm/8369

16. Torres-Poveda K, Bahena-Roman M, Madrid-Gonzales C. Role of II-10 and TGF- $\beta 1$ in local immunosupression in HPVassociated cervical neoplasia. World J. Clin. Oncol. 2014;5(4):753-63. https://doi.org/10.5306/wjco.v5.i4.753 PMid:25302175 PMCid:PMC4129538

17. Zarochentseva NV, Malinovskaya VV, Torshina ZV. Particularities of immunocorrecting therapy in pregnant women having papillomavirus infection. Russian Bulletin Obstetrician-Gynecologist. 2014;14(3):57-63. 